\title{
Sobre algumas contradições da forma escolar
}

\section{About some contradictions of school form}

\section{Marcos Villela Pereira}

Doutor em Educação, professor titular do Programa de Pós-Graduação em Educação da Pontifícia Universidade Católica do Rio Grande do Sul (PUCRS), Porto Alegre, RS - Brasil, e-mail: marcos.villela@pucrs.br

\section{Resumo}

Este trabalho visa a colocar em questão algumas contradições que aparecem na forma escolar de um modo geral e, em particular, no fenômeno da educação brasileira contemporânea. São elas: que o direito à educação converteu-se na escolarização obrigatória, transformando o que era uma reivindicação política em uma condição compulsória, cuja desobediência é punível pela lei; e que esse modelo de educação-para-todos vem contribuindo para modelar a escola como uma "instituição total". Pautado no resgate histórico de alguns ideais iluministas e da evolução do capitalismo contemporâneo, o artigo chega à atual realidade brasileira com o intuito de especular alguns modos de funcionamento da escola como instituição que busca emancipar e, ao mesmo tempo, controlar.

Palavras-chave: Forma escolar. Direitos humanos. Instituição total. 


\section{Abstract}

This paper aims to question some contradictions that appears in general school form and, specifically, in the phenomenon of contemporary Brazilian education. They are: the right to education became compulsory in school, turning what was a political claim on a compulsory condition, whose disobedience is punishable by law, and that this model of education-for-all has been contributing to modeling school as a "total institution". Lined in the historical review of some ideals of the Enlightenment and the evolution of contemporary capitalism, the article reaches the current Brazilian reality with the intention to speculate some modes of operation of the school as an institution that seeks to empower and at the same time, control.

Keywords: School form. Human rights. Total institution.

\section{Introdução}

O que vai nortear esta reflexão é a especulação de algumas contradições que aparecem na condição escolar de um modo geral e, em particular, no fenômeno da educação brasileira contemporânea. São eles: que o direito à educação converteu-se na escolarização obrigatória, transformando o que era uma reivindicação política em uma condição compulsória, cuja desobediência é punível pela lei; e que esse modelo de educação-para-todos vem contribuindo para modelar a escola como uma "instituição total".

Vou buscar algumas referências históricas para colocar essas questões. Nos idos de 1500, temos na escola o principal veículo de formação do indivíduo moderno. Cabe à escola a tarefa de formaro indivíduo, atendendo a uma série de particularidades: a formação deve começar na infância e demanda um lugar específico, que agregue as condições necessárias para esse trabalho. Um lugar que se organize em torno do desenvolvimento da inteligência, do aumento do repertório de conhecimentos, da aprendizagem de regras e normas disciplinares, dos discursos e práticas que vão ensinar o indivíduo a governar e ser governado. Na esteira da constituição do mundo 
moderno, os sujeitos devem aprender a conduzir-se, a serem conduzidos e conduzir os outros no âmbito da vida coletiva das nações. Caberá à escola, portanto, formar o indivíduo intelectualmente, dando-lhe acesso a conhecimentos e verdades que se produzem no âmbito da ciência e levando-o a aderir (e submeter-se) a um sistema de crenças não mais em verdades reveladas, mas em verdades produzidas a partir do exercício de uma certa forma de racionalidade. O sujeito deve ir à escola para aprender coisas, isto é, para ter acesso a um vasto conjunto de conhecimentos, e para aprender o modo como se chega a essas coisas, isto é, para aprender a pensar, aceitar e produzir verdades sobre si e sobre o mundo. Por outro lado, caberá à escola formaro indivíduo morale politicamente, ensinando-o a conduzir a sua própria vida. O indivíduo vai aprender a obedecer conscientemente, reflexivamente (não mais porque sofre a ameaça da violência caso desobedeça, como nos tempos anteriores a esse período, na sociedade de governo soberano). Isto é, a escola vai levá-lo a aderir a um sistema de governo que funciona com base em verdades acerca do bem e do mal, do certo e do errado, ancoradas em conhecimentos oriundos da forma refletida de conduzir a sociedade de modo racional. Racionaliza-se o cotidiano e daí extraem-se conhecimentos que passarão a funcionar como um sistema de verdades, ao qual os indivíduos devem se submeter. Para que esse sistema funcione, cada vez mais regras vão sendo produzidas e, consequentemente, cada vez mais aparatos de disciplina e controle vão sendo inventados para assegurar que as regras sejam cumpridas. E como o que a sociedade moderna quer é que o próprio sujeito dê conta de governar-se, ou seja, que ele internalize essas normas e regras, vai desenvolver na escola um importante dispositivo para essa função.

Entre os anos de 1776 e 1777, Kant, em seus escritos sobre educação, já dizia que

as pessoas devem estar atentas à finalidade da natureza, mas devem, sobretudo, cuidar do desenvolvimento da humanidade, e fazer com que ela se torne não somente mais hábil, mas ainda mais moral e, por último - coisa ainda mais difícil -, empenhar-se em conduzir a posteridade a um grau mais elevado do que eles atingiram (KANT, 1996, p. 26).

Na educação, Kant continua, o homem deve ser disciplinado, tornarse culto, tornar-se prudente e cuidar da moralização. Como culminância desses preceitos, ele afirma que "um dos maiores problemas da educação é o de 
poder conciliar a submissão ao constrangimento das leis com o exercício da liberdade. $\mathrm{Na}$ verdade, o constrangimento é necessário. Mas de que modo cultivar a liberdade? É preciso habituar o educando a suportar que a sua liberdade seja submetida ao constrangimento de outrem e que, ao mesmo tempo, dirija corretamente a sua liberdade" (KANT, 1996, p. 34).

Enfim, a dupla tarefa da escola se pauta no desenvolvimento da razão que ilumina o mundo e cujo movimento põe em funcionamento um sistema de saberes e na materialização de um aparato disciplinar e vigilante que atende a um sistema de poder. De fato, nem são dois sistemas, são um só. São dois lados de uma mesma moeda. É um sistema de saberes que, para existir, deriva em aparatos de poder que o façam funcionar. A dupla tarefa da escola se realiza por meio de um currículo, um conjunto de conhecimentos, conteúdos e atividades que devem ser desenvolvidos de modo sistemático, e por meio de um regulamento, um conjunto de regras - explícitas ou não - que vão desenvolver nas crianças a capacidade de governar, de governarse e de serem governadas.

Mas isso não significa que a formação escolar apresenta resultados meramente negativos. A formação escolar não resulta apenas em docilização, opressão e submissão generalizadas. De fato, o que se requer é que essa mesma razão que serve à ilustração também sirva de ferramenta de análise dessas condições de submissão. Que a razão esclarecida possa voltar-se para identificar que verdades nos governam, a que jogos estamos submetidos, que sistemas nos regulam. Não com o intuito de livrar-nos dessa condição de ser governados, mas para que tenhamos a possibilidade de colocar em questão esse estado de ser e, por consequência, pensar se queremos ser governados assim, por causa disso, em nome desses princípios, em vista de tais objetivos, por meio de tais procedimentos (FOUCAULT, 1995).

O trunfo da razão crítica é nos possibilitar o entendimento dessa condição de governamentalidade que nos configura, entender como funcionam os jogos de saber e de poder que nos governam. Não se trata, como nos ensina Foucault, de opor-se ao governo, de não querer ser governado de jeito nenhum; trata-se, isso sim, da possibilidade de pensar em não ser governado assim, não para isso, não por eles.

Por que me tornei quem sou? Por que faço o que faço? Por que ajo dessa maneira? Por que penso o que penso? - essas questões nos levam a entender o sistema de crenças que eu aceitei e ao qual estou submetido. De maneira bem resumida, a razão crítica vai me possibilitar entender como 
e por que essas ideias se legitimaram como verdadeiras. Voltando a citar Foucault, "a crítica é o movimento pelo qual o sujeito se arroga o direito de interrogar a verdade sobre seus efeitos de poder e ao poder sobre seus discursos de verdade" (FOUCAULT, 1995).

Ora, assim entendido, a escola, em sua dupla função, também desempenha um duplo papel: o de gerar condições para aceitação elegitimação de certas verdades, validando certa forma de governo, e o de permitir ou possibilitaro entendimento desses mecanismos, na direção de facultar ao sujeito uma tomada de decisão. Ou seja, tanto a escola funciona como um aparelho ideológico que fabrica determinada forma de governo, quanto possibilita o esclarecimento que pode levar à emancipação daquele sistema (vale lembrar, se trata de escapar dessa forma de governo em direção a uma outra).

De qualquer maneira, seja por um motivo ou seja por outro, a escola tornou-se o principal dispositivo de formação na sociedade ocidental moderna. A escola tornou-se a principal instituição responsável pela educação. E essa condição dicotômica da educação escolar, que conforma e que emancipa, nunca será resolvida. Caberá aos projetos políticos (sociais, culturais, etc.) que sustentarão esse empreendimento dar mais ênfase a um aspecto ou a outro.

Do ponto de vista dos ideais revolucionários na França, por exemplo, considerando as ideias de Condorcet expressas no seu Relatório sobre a Instrução Pública, só por meio da instrução seria possível tornar efetiva a "igualdade". Assentada sobre a desigualdade econômica, essa perspectiva de igualização, por parte da escola revolucionária, contribui efetivamente para a constituição do sujeito liberal, conformando-o a um modelo de sociedade que naturaliza essas desigualdades e a consequente dominação de uma classe por outra.

No extremo oposto dessa concepção podemos encontrar o entendimento de Gramsci que, por reconhecer o poder da hegemonia e o papel dos intelectuais, propõe a Escola Única, cujo objetivo é a formação em cultura geral, humanista, que equilibre de modo justo o desenvolvimento da capacidade de trabalhar manualmente (tecnicamente e industrialmente) e o desenvolvimento das capacidades de trabalho intelectual. Ou seja, que possibilite ao aluno o acesso a uma condição crítica a ponto de poder reconhecer e libertar-se do jugo da classe dominante.

Cada projeto político, cada modelo de sociedade, cada modo de organização tentará dar ênfase ao aspecto da escola que mais lhe convier, 
para a consecução de seus objetivos. Cada proposta política definirá que características, que tipo de indivíduo precisa ou deseja que seja formado e tratará de impingir à escola uma forma que favoreça a formação desse tipo de homem.

E é a prática escolar que, em última análise, como todos os elementos que dela fazem parte, dará o tom da formação com vistas a conformar ou emancipar. Como esse conjunto de elementos é completamente heterogêneo, como não há como "emparelhar" todas as pontas, sempre haverá a possibilidade da resistência, da brecha, da burla do projeto principal, seja ele qual for.

Então, com a escola funcionando dessa maneira, a favor e contra gregos e troianos, viemos transformando a sociedade e o mundo ocidental ao longo desses 500 anos. As modificações ocorridas no âmbito da forma escolar foram resultado de iniciativas sempre dirigidas ao aperfeiçoamento das funções da escola. Pedagogias, metodologias, modelos curriculares, organizações temporais e espaciais, enfim: um sem-número de providências de cunho operacional se processaram ao longo da história com vistas a tornar a escola cada vez mais eficiente em sua missão de formar os cidadãos.

Entretanto, aquela perspectiva de igualdade absoluta presente no ideário liberal nunca se afastou das pautas de reivindicação ou das propostas de governo, qualquer que fosse a sua orientação política. O direito de todos à educação sempre esteve no horizonte da sociedade.

No caso brasileiro, o clamor da "educação para todos" também aparece ao longo da história, ora associado ao progresso e ao nacionalismo caricatos (como no primeiro Governo Vargas, em que a Constituição de 34 estabelece a gratuidade e a obrigatoriedade do ensino primário) (FREITAG, 1986), ora associado ao ideal de emancipação da classe oprimida por um capitalismo cada vez mais selvagem (como as campanhas pela escola pública desencadeadas em 1959 pelos educadores e intelectuais em seu manifesto contra o "Substitutivo Lacerda") (FERNANDES, 1966).

Chegamos à última década do século XX empurrados por ventos muito diferentes mas muito parecidos. No texto da Constituição Federal, promulgada em 1988, fica estabelecida a educação como "direito de todos e dever do Estado e da família" (art. 205), e disposto o "ensino fundamental obrigatório e gratuito, inclusive para aqueles que a ele não tiveram acesso na idade própria" (art. 208, inciso I), destacando no parágrafo $1^{\circ}$ que "o acesso ao ensino obrigatório e gratuito é direito público subjetivo". Em 
1990 é promulgada a Lei n. 8.069 (BRASIL, 1990), instituindo o Estatuto da Criança e do Adolescente, que estabelece que "a criança e o adolescente têm direito à educação, visando ao pleno desenvolvimento de sua pessoa, preparo para o exercício da cidadania e qualificação para o trabalho" (art. 53) e que "os pais ou responsável têm a obrigação de matricular seus filhos ou pupilos na rede regular de ensino" (art. 55).

Em 1993, a partir da consolidação do Fórum Internacional de Educação para Todos na Conferência de Jomtien, na Tailândia, ocorrida em 1990, o Brasil vê nascer o Plano Decenal Educação para Todos pelas mãos do governo do presidente Itamar Franco. Em 1996, foi a vez da Lei de Diretrizes e Bases da Educação Nacional estabelecer que "a educação, dever da família e do Estado, inspirada nos princípios de liberdade e nos ideais de solidariedade humana, tem por finalidade o pleno desenvolvimento do educando, seu preparo para o exercício da cidadania e sua qualificação para o trabalho" (art. $2^{\circ}$ ). Mais objetivamente, em seu artigo $4^{\circ}$ ela repete o disposto na Constituição Federal: "o dever do Estado com educação escolar pública será efetivado mediante a garantia de [entre outras indicações] ensino fundamental, obrigatório e gratuito, inclusive para os que a ele não tiveram acesso na idade própria" (art. 4º inciso I) (BRASIL, 1996).

Para o Banco Mundial, outro importante organismo de regulação,

a educação, especialmente a primária e a secundária, ajuda a reduzir a pobreza aumentando a produtividade do trabalho dos pobres, reduzindo a fecundidade, melhorando a saúde, e dota as pessoas de atitudes de que necessitam para participar plenamente na economia e na sociedade (SHIROMA, 2004, p. 74-75).

Em 2007, por fim, é disposto por decreto o Plano de Metas Compromisso Todos pela Educação, cuja tarefa é a "conjugação dos esforços da União, Estados, Distrito Federal e Municípios, atuando em regime de colaboração, das famílias e da comunidade, em proveito da melhoria da qualidade da educação básica" (art. $1^{\circ}$ ), expressa pela perspectiva de consecução de 28 diretrizes. Dentre elas, destaco a pretensão de "alfabetizar as crianças até, no máximo, os oito anos de idade" (art. $1^{\circ}$, inciso II) e "acompanhar e avaliar, com participação da comunidade e do Conselho de Educação, as políticas públicas na área de educação e garantir condições, sobretudo institucionais, de continuidade das ações efetivas, preservando a memória daquelas realizadas" (art. 1º, inciso XX) (BRASIL, 2007). 
Minha intenção, ao recuperar esses fatos todos, foi mostrar que o projeto liberal-burguês de educação escolar como instância formativa para acompanhar as exigências evolutivas do capitalismo continua presente nas políticas educacionais contemporâneas e que o direito à educação converteuse na escolarização obrigatória, convertendo o que era uma reivindicação em uma condição compulsória, cuja desobediência é punível pela lei. Passo ao último segmento do texto, explorando a ideia de que esse modelo de educação para todos faz da escola uma "instituição total".

A ideia de "instituição total" foi muito bem trabalhada por Goffman (2001, p. 11), que a define como "um lugar, um local de residência e trabalho onde um grande número de indivíduos com situação semelhante, separados da sociedade mais ampla por considerável período de tempo, levam uma vida fechada e formalmente administrada". As instituições totais podem ser de vários tipos: manicômios, quartéis e prisões. Elas estabelecem, a partir do controle da liberdade, uma rotina rigorosa sob uma autoridade institucional que se faz presente a partir de um plano racional de regras (explícitas e implícitas) que devem ser constantemente observadas. Em uma "instituição total", todas as atividades serão realizadas num mesmo local e sob uma autoridade central, observando que os indivíduos deverão fazer as mesmas coisas, em conjunto, sob a forma de atividades diárias com rigor de horário.

Os indivíduos vão parar lá dentro a partir de seu enquadramento por certo juízo elaborado a partir de uma determinada verdade acerca de sua condição. Um crime, um ato de loucura, uma infração, um diagnóstico são suficientes para que ele seja tolhido de sua condição e levado para lá. Em suma, por efeito de certo regime de verdade produz-se um equipamento que encarna uma multiplicidade de relações de forças, em um jogo permanente de lutas e enfrentamentos que visa a produzir certo tipo de sujeito.

A escola, de certa maneira, acaba por incorporar vários desses traços a partir do estabelecimento de objetivos tais como a erradicação do analfabetismo, a escolarização obrigatória e a escola em tempo integral. Evidentemente, ela não reproduz o modelo tradicional dos manicômios ou das prisões, ícones da sociedade disciplinar. A evolução do capitalismo e as mutações na sociedade contemporânea contribuíram para o aparecimento de novos aparatos de controle, de forma que novas relações sociais foram sendo arranjadas por efeito de poderes microfísicos e por modos de funcionamento dos saberes. O próprio discurso em favor dos valores de 
liberdade e igualdade produziu um campo de verdades que vem reger uma série de movimentos na organização da sociedade. Como nos diz Boaventura Santos (1997), enquanto forem concebidos como direitos humanos universais, os direitos humanos tenderão a operar como localismo globalizado, uma forma de globalização de cima para baixo, serão sempre um instrumento do choque de civilizações.

Verdades como essas é que vão encarnar em uma escola-paratodos-e-o-tempo-todo. Uma escola que, apesar de ser constitucionalmente um direito subjetivo, é condição para a concessão de auxílios do governo e cuja não frequência representa a probabilidade de uma importante sanção. Uma escola que, apesar de revestir-se de uma aura emancipatória, também controla e normaliza. Uma escola que arroga para si a tarefa de manter a criança e o adolescente o máximo de tempo possível longe das ruas, da cidade, do mundo, especialmente em nome do poder de mantê-los sob vigilância, longe das infrações e desvios morais.

Inúmeros são os trabalhos que jogaram luz sobre as formas de funcionamento dos aparatos de controle da escola: controle do espaço, organização do tempo, configuração do currículo, disciplinamento do corpo, uniformização de hábitos, exames de consciência, comprovações de aprendizagem, conselhos de classe, enfim. Todos buscam mostrar evidências de um aspecto do funcionamento ambíguo dessa instituição.

Como nas "instituições totais", também na escola o aluno (e o professor) enfrenta a condição de conceber a si e aos outros a partir de estigmas, apelidos ou estereótipos (em sua maioria hostis) em resposta a uma necessidade de identificar-se e identificar os outros no interior de um novo sistema, com novos critérios. Também na escola o aluno (e o professor) passa por uma carreira moral de "desaculturamento", um percurso que pauta a aprendizagem e a aquisição de certos valores e hábitos a partir da desaprendizagem e perda de outros. Também na escola, ao vivenciar experiências de socialização, os alunos (e os professores) "desenvolvem apoio mútuo e resistência a um sistema que os forçou à intimidade numa única comunidade igualitária de destino" (GOFFMAN, 2003, p. 55), forjando pares, grupos, gangues ou "panelinhas" como uma resposta tática, de adaptação ou de resistência para sobreviver ao dia a dia. Também na escola o aluno (e o professor) é confrontado com a existência de sujeitos exemplares, superiores moral e intelectualmente, que lhes devem servir de modelo e contraponto. Também na escola o aparato burocrático formaliza e regula 
a vida dos alunos e professores. Também aí as regras da casa, de modo geral invisíveis, instalam e legitimam rituais que vão deste o trote aos calouros até a periodicidade das reuniões ou o modo de redação da ata. Por fim, também a escola funda-se nos problemas da sociedade em que se insere, tomando a realidade social como ponto de partida e de chegada de seu projeto.

Enfim. Quero concluir este ensaio recolocando as questões que me mobilizaram inicialmente: o direito à educação, que converteu-se na escolarização obrigatória, fazendo daquilo que era uma reivindicação política uma condição compulsória, e o modelo de educação-para-todos que tem contribuído para estabelecer a escola como uma "instituição total".

Diante disso, como proceder? O que fazer? Como resolver essas contradições? Longe de pretender uma resposta objetiva a esse questionamento, prefiro me ater à ideia de que não há como obter-se a liberdade senão submetendo-se à sociedade. A liberdade individual já era uma utopia forte na época das Luzes. E continua sendo. Com uma diferença importante: já não nos deixamos mais capturar pelo modelo daquela utopia, que pretendia a liberdade como algo absoluto e localizava essa forma de liberdade fora de nós mesmos, fora da sociedade, fora do mundo. Nossa liberdade é um acidente. Nossa liberdade é uma contingência.

\section{Referências}

BRASIL. Constituição (1988). Constituição: República Federativa do Brasil. Brasilia, DF: Senado Federal, 1988. Disponível em: < http://www.senado.gov.br/ sf/legislacao/const>. Acesso em: 15 dez. 2009.

BRASIL. Lei n. 8.069, de 13 de julho de 1990. Dispõe sobre o estatuto da criança e do adolescente, e da outras providencias. Diário Oficial [da] República Federativa do Brasil, Poder Legislativo, Brasília, DF, 16 jul. 1900. p. 13563. Disponível em: <http://www6.senado.gov.br/legislacao/ListaTextoIntegral. action?id $=75648>$. Acesso em: 23 nov. 2009.

BRASIL. Lei n. 9.394, de 20 de dezembro de 1996. Estabelece as diretrizes e bases da educação nacional. Diário Oficial [da] República Federativa do Brasil, Poder Legislativo, Brasilia, DF, 23 dez. 1996. p. 27833. Disponível em: < http://www6.senado. gov.br/legislacao/Lista'TextoIntegral.action?id=75723>. Acesso em: 23 jul. 2009. 
BRASIL. Decreto n. 6.094, de 24 de abril de 2007. Dispõe sobre a implementação do plano de metas compromisso todos pela educação, pela união federal, em regime de colaboração com municípios, distrito federal e estados, e a participação das famílias e da comunidade, mediante programas e ações de assistência técnica e financeira, visando a mobilização social pela melhoria da qualidade da educação básica. Diário Oficial [da] República Federativa do Brasil, Poder Legislativo, Brasília, DF, 24 abr. 2007. Disponível em: <http://www6.senado.gov.br/ legislacao/ListaTextoIntegral.action?id=234583 >. Acesso em: 23 dez. 2009.

FERNANDES, F. Educação e sociedade no Brasil. São Paulo: Dominus, 1966.

FOUCAULT, M. Crítica y Aufklärung [Qu'est-ce que la Critique?]. Revista de Filosofia ULA, v. 8, p. 5-30, 1995. Disponível em: <http://www.saber.ula.ve/ cgi-win/be_alex.exe?Documento=T016300000327/0\&term_termino_2=d:/ alexandr/db/ssaber/Edocs/centros_investigacion/csi/publicaciones/papers/ davila-critica-aufklarung.pdf>. Access in: 18 dez. 2009.

FREITAG, B. Escola, estado e sociedade. 6. ed. São Paulo: Moraes, 1986.

GOFFMAN, E. Manicômios, prisões e conventos. 7. ed. São Paulo: Perspectiva, 2001.

KANT, I. Sobre a pedagogia. Piracicaba: Ed. UNIMEP, 1996.

SANTOS, B. de S. Por uma concepção multicultural de direitos humanos. Lua Nova: Revista de Cultura e Política, n. 30, p. 105-124, 1997.

ShIROMA, E. O.; MORAES, M. C. M. de; EVAnGELISTA, O. Política educacional. 3. ed. Rio de Janeiro: DP\&A, 2004.

Recebido: 20/10/2009

Received: 10/20/2009

Aprovado: 20/12/2009

Approved: 12/20/2009 